\title{
Escritura académica en el pregrado: un caso de relación entre docente, alumno y las disciplinas
}

John Jairo Sánchez Muñoz ${ }^{1}$

1 Docente de lectoescritura adscrito al Departamento de Humanidades, Universidad Santo Tomás. Magister en Filología Hispánica del Consejo Superior de Investigaciones Científicas de la ciudad de Madrid. Candidato a Magíster en Evaluación y Calidad de la Educación en la Universidad Externado de Colombia.
Correspondencia: Dr. John Jairo Sánchez Muñoz,jhonsanchez@usantotomas.edu.co

Como citar: Sánchez JJ. Escritura académica en el pregrado: un caso de relación entre docente, alumno y las disciplinas. Cuarzo 2015; 21 (1): 1-3.

Recibido: 3 de marzo de 2015 Aceptado: 1 de junio de 2015. Publicado: 30 de junio de 2015.

Licencia creative commons (c)

\section{Resumen}

En este artículo se realiza una reflexión sobre la escritura académica en el nivel de pregrado de la formación educativa en la universidad, comentando sus principales dificultades y las estrategias que se han implementado institucionalmente para enfrentarla, con la finalidad de contribuir a la generación de conocimiento en torno a las competencias comunicativas en el contexto académico.

PALABRAS CLAVE: escritura académica, competencias y habilidades comunicativas, estrategias institucionales.

\section{Abstract \\ Academic writing in undergraduate: a case of relationship among teacher, student and the disciplines}

This article presents a reflection on the academic writing is done at the undergraduate level of educational training at the university, remarking their main difficulties and strategies that are institutionally implemented to address it, in order to contribute to the generation of knowledge in about communication skills in the academic context.

KEYWORDS: academic writing skills and communication skills, organizational strategies.

\section{Introducción}

En el contexto educativo de la actual sociedad del conocimiento, es necesario enfocar los procesos formativos hacia el cumplimento de diversos objetivos personales, institucionales y sociales, y todos deben estar encaminados hacia el mejoramiento de las competencias comunicativas de cada uno de los partícipes en el proceso de enseñanza-aprendizaje. Para lograr dichas metas se requiere reflexio- 
nar acerca de cómo cualificar y transformar las prácticas pedagógicas, con el fin de hacer de la educación un acto pertinente, contextualizado y transformador de la sociedad (1). Si bien esta afirmación puede ser interpretada y sustentada desde diversas perspectivas, para este documento, el enfoque central girará en torno a una posición crítica respecto a los procesos de enseñanza-aprendizaje de la escritura en la educación superior. Por consiguiente, surge el siguiente interrogante, ¿por qué a pesar de que existen políticas educativas, investigaciones exhaustivas, métodos diversos de enseñanza, variedad de literatura enfocada al mejoramiento de procesos de escritura en la educación superior, cursos, talleres y mil recursos más, se evidencia de manera constante numerosos problemas o dificultades para representar o construir conocimiento mediante un discurso textual?

Para intentar dar respuesta al interrogante planteado, iniciaré afirmando que una de las tareas en las que permanentemente se hacen grandes esfuerzos por parte de los docentes, de las instituciones educativas y del gobierno, es en el aprendizaje y la puesta en práctica de estrategias de producción textual. Tanto así, que el objetivo fundamental de las políticas estatales, es el de poder fortalecer la competencia comunicativa de los educandos desde los inicios de la vida escolar, hasta el paso por la educación superior (2). Sin embargo, a pesar de los esfuerzos realizados para lograr un desempeño sobresaliente en el mejoramiento de habilidades de producción escrita, la realidad educativa demuestra lo contrario. Una evidencia de esta afirmación, es que en la práctica, el desempeño en la elaboración textual universitaria es muy bajo, ya que desde las diversas áreas del conocimiento generalmente se tiene la falsa creencia de que escribir es algo mecanizado que fue aprendido antes de ingresar a los estudios superiores, y que no debe ser enseñado (3).

En segunda medida otra solución al interrogante radica en que, desde la práctica profesional, es posible sustentar una constante, y es el que un gran número de docentes de pregrado que conforman diversos programas de formación profesional, dan por sentado que sus estudiantes saben interpretar y redactar textos de calidad académica científica (4). Más sin embargo, es necesario agregar un ingrediente a esta receta, y es que ha quedado demostrado que en numerosas ocasiones, no en todas, los mismos docentes universitarios que encargan a sus alumnos presentar escritos de calidad académica, no conocen, o además confunden categorías textuales o normas de redacción.

\section{La escritura académica en el pregrado}

Al hacer un análisis de la situación relacionada con la escritura académica en el pregrado, me atrevería a plantear que, con frecuencia, en los contextos de educación superior, los estudiantes deben acudir a fuentes externas para poder cumplir con los requerimientos de redacción. A lo que iría en contravía por lo planteado por Carlos Vasco quien afirma que la enseñanza.

Es la actividad del maestro que corresponde a uno de los dos sentidos de la relación maestroalumno(s), juntamente con uno de los dos sentidos de la relación maestro microentorno(s), en cuanto el maestro trata de reconfigurar los microentornos para potenciar la relación microentorno(s)- alumno(s) de tal manera que en lo posible esté sintonizada y no desfasada de la primera (1).

Desde esta afirmación, los docentes, en este caso universitarios, deberían tomarse un instante en identificar las falencias o debilidades en cuanto a lo que escritura se refiere, y así poder tomar crear estrategias didácticas para lograr desarrollo de las habilidades comunicativas de sus estudiantes. Partiendo de lo mencionado anteriormente, es posible manifestar que la problemática va más allá de las prácticas pedagógicas, en las cuales el docente reflexione a partir de sus experiencias de aula y genere cambios realmente significativos.

Es verdad que la pedagogía, o más bien la didáctica como propuesta de métodos de enseñanza, puede convertirse, y de hecho a veces se convierte, en una excusa para no seguir aprendiendo e investigando en la propia área en la que se ejerce la docencia, y en un sustituto muy pobre para la falta de conocimientos, de entusiasmo, de espíritu investigativo, y de compromiso con la ciencia respectiva (1).

\section{Estrategias institucionales para mejorar la es- critura académica en las universidades}

En la actualidad un gran número de universidades ha detectado a través de investigaciones, prácticas académicas y conversaciones entre docentes y alumnos, que es posible generar cambios significativos frente a la escritura académica. Como resultado de estas decisiones y políticas institucionales, un gran número de entidades de educación superior en Colombia, han podido sobresalir en lo 
que respecta a calidad educativa, mejores resultados en pruebas saber pro, entre otras.

Se hace necesario repensar y fortalecer la escritura y la lectura en su función epistémica; de lo contrario, difícilmente se construirán condiciones para consolidar las capacidades científicas que, a su vez, son la base para un incremento de la productividad académica en el país. Aquí queda planteado un reto concreto de política institucional. Es importante, igualmente, repensar la forma como estamos vinculando a nuestros estudiantes a las comunidades de práctica y a las dinámicas de producción, comunicación, circulación y validación del conocimiento $(5,6)$.

\section{Conclusiones}

Aprender y enseñar a escribir y hacerlo bien implica por un lado, el cambio de la práctica pedagógica, permitiendo una transversalidad e interdisciplinariedad de los procesos escriturales. De esta manera tanto docentes como estudiantes pueden desarrollarse como pensadores a través de la construcción de proceso cognitivos fundamentados en la producción textual y en los procesos comunicativos. Por otro lado, es necesario retomar los actos comunicativos desde la práctica contextualizada con el fin de dar sentido y papel activo a la formación del estudiante. Por lo cual es innegable que para hacer que los alumnos muestren gusto por la construcción de conocimiento a través de producción textual escrita, es preciso que el docente modifique las condiciones con las cuales se accede al conocimiento con el fin de generar un aprendizaje para la vida, con carácter social e interdisciplinario y reforzar la concepción incluyente e integradora de la educación con otros aspectos con los que interacciona, como la cultura, la sociedad y la tecnología.

\section{Referencias}

1. Vasco, C. (1989) Algunas reflexiones sobre pedagogía y didáctica. Disponible en: http://ineduga.webcindario.com/ pedagogiadidactica.pdf

2. Molina-Natera, V. (2012). Escritura a través del currículo en Colombia: situación actual y desafíos. Magis. Revista Internacional de Investigación en Educación, 5(10) 93-108. Recuperado de http://www.redalyc.org/articulo. oa?id=281024896006

3. Carlino, P. (2003). Alfabetización Académica: Un Cambio Necesario, algunas Alternativas Posibles. Educere, 6(20) 409-420. Recuperado de http://redalyc.org/articulo. oa?id=35662008

4. Villalobos J. (2007). La enseñanza de la escritura a nivel universitario: fundamentos teóricos y actividades prácticas basados en la teoría sociocultural. Educere, 11(36) 61-71. Recuperado de http:// www.redalyc.org/articulo. oa?id=35617701009.

5. Pérez, M y Rincón, G. (2013). ¿Para qué se lee y se escribe en la universidad colombiana? Un aporte a la consolidación de la cultura académica del país, Bogotá: Pontificia Universidad Javeriana.

6. Peña, L. (2009). La competencia oral y escrita en la educación superior. Documento inédito. Ministerio de Educación Nacional. 